\title{
Liquid Gallium Electrode Confined in Porous Carbon Matrix as Anode for Lithium Secondary Batteries
}

\author{
Kyu T. Lee, Yoon S. Jung, Taeahn Kim, Chang H. Kim, Jun H. Kim, \\ Ji Y. Kwon, and Seung M. Oh${ }^{*, z}$
}

Department of Chemical and Biological Engineering, and Research Center for Energy, Conversion and Storage, Seoul National University, Seoul 151-744, South Korea

\begin{abstract}
A liquid gallium electrode confined in a porous carbon matrix was prepared by vaporization and pyrolysis of $\mathrm{Ga}(\mathrm{III})$ phthalocyanine chloride on a nanosized $\mathrm{Ga}_{2} \mathrm{O}_{3}$ powder surface, which was followed by carbothermal reduction of $\mathrm{Ga}_{2} \mathrm{O}_{3}$ by a carbon matrix. When the electrode was charge/discharge cycled, the liquid Ga component was restored to its original liquid state at the final stage of delithiation, such that any electrode failure modes, for instance, crack formation and electric disconnection that are caused by severe volume change associated with multistage, solid-state $\operatorname{Li}_{x} \mathrm{Ga}(0<x \leq 2)$ phase transitions, are self-healed by cohesion between liquid Ga droplets.

(C) 2007 The Electrochemical Society. [DOI: 10.1149/1.2823262] All rights reserved.
\end{abstract}

Manuscript submitted September 18, 2007; revised manuscript received November 7, 2007.

Available electronically December 26, 2007.

Li-alloy materials ( $\mathrm{Si}, \mathrm{Sn}$, and $\mathrm{Sb}$ ) have been projected as a promising alternative to carbon-based anodes for lithium secondary batteries as they have a high theoretical specific capacity ${ }^{1-5}$ Until now, however, Li-alloy materials have not been used as anodes in practical batteries due to an unsatisfactory cycle life that is largely caused by a severe volume expansion/contraction during the alloying and dealloying reaction. Such a volume change is known to induce crack formation, detachment of active materials from the current collector, and/or breakdown of the electronically conductive network within the electrode layer, which would eventually deactivate their $\mathrm{Li}^{+}$storage ability. ${ }^{6-10} \mathrm{As}$ an approach to solve or at least alleviate this problem, many composite materials including matrix phases to buffer the volume change have been introduced, with which a partial improvement has been achieved. ${ }^{11-15}$

In this article, we propose another approach to solve the problems of volume change, which is the use of liquid-state alloy materials as the negative electrode for lithium secondary batteries. The idea has been developed on the basis of an assumption that the alloying/dealloying reaction of liquid electrode is chemically reversible, that is, the liquid electrode is restored to its liquid state even if it experiences a solid-state intermediate phase along with alloying/ dealloying reactions. If the reaction is reversible, any failure modes encountered with massive volume change (crack formation, detachment of active materials, and/or breakdown of the electronically conductive network) can be self-healed at the final stage of the dealloying period, because once the liquid phase is formed at this stage, the liquid droplets are merged together due to high surface tension and fluidity inherent to liquid-state materials. The net result would be a restoration to the initial state without any cracks and isolated particles.

In this article, we have ascertained the self-healing concept using a liquid Ga electrode (melting point $29.8^{\circ} \mathrm{C}$ ) that is confined in a porous carbon matrix. The idea for the use of porous carbon was to confine the solid-state $\mathrm{Li}_{x} \mathrm{Ga}$ particles at the void space to minimize their detachment. In addition, the crack formation and other undesirable features associated with volume change of embedded $\mathrm{Ga}$ would be suppressed by the squeezing action provided by the porous carbon matrix. ${ }^{14}$ With this premise in mind, we prepared liquid Gaconfined porous carbon electrodes and their electrochemical performance was examined. The embedded liquid $\mathrm{Ga}$ was prepared from $\mathrm{Ga}_{2} \mathrm{O}_{3}$ powder by a carbon coating and subsequent carbothermal reduction. The favorable role of the porous carbon matrix is highlighted by comparing the results for this and a matrix-free liquid $\mathrm{Ga}$ electrode.

\footnotetext{
* Electrochemical Society Active Member.

zz-mail: seungoh@snu.ac.kr
}

\section{Experimental}

Preparation of liquid Ga-confined porous carbon- Nanometersized $\mathrm{Ga}_{2} \mathrm{O}_{3}$ powder was prepared by high-energy mechanical ballmilling of $\mathrm{Ga}_{2} \mathrm{O}_{3}$ powder $(99.99 \%$, Aldrich) in ethanol medium. After milling for $3 \mathrm{~h}$, the solvent was evaporated at $60^{\circ} \mathrm{C}$. The resulting nanometer-sized $\mathrm{Ga}_{2} \mathrm{O}_{3}$ powder was mixed with gallium(III)-phthalocyanine chloride (Aldrich) (1:4 in weight ratio) and heated at $800^{\circ} \mathrm{C}$ for $3 \mathrm{~h}$ for the carbonization of organic moiety, which was followed by heat-treatment at $1000^{\circ} \mathrm{C}$ for $3 \mathrm{~h}$ under $\mathrm{Ar}$ atmosphere for carbothermal reduction of $\mathrm{Ga}_{2} \mathrm{O}_{3}$ powder.

$\mathrm{X}$-ray diffraction (XRD) patterns were obtained with a D8Brucker diffractometer equipped with $\mathrm{Cu} K \alpha$ radiation. Highresolution transmission electron microscope (HR-TEM) images were obtained using a JEOL JEM-3010. The $\mathrm{N}_{2}$ adsorption and desorption isotherms were collected at $77 \mathrm{~K}$ with a Micrometrics ASAP2010 gas adsorption analyzer. The Ga content in liquid Gaconfined porous carbon $(\mathrm{Ga}-\mathrm{C})$ was analyzed using the thermogravimetric analysis (TGA) profiles that were obtained from room temperature to $1000^{\circ} \mathrm{C}$ at $20^{\circ} \mathrm{C} \mathrm{min}-1$ in air with a TA Instruments Q 600 simultaneous differential scanning calorimeter/TGA analyzer.

Electrochemical characterization.-The composite electrode was prepared by spreading a slurry mixture of $\mathrm{Ga}-\mathrm{C}$ powder, poly(vinylidene fluoride) (as binder), and super $\mathrm{P}$ carbon black (as a carbon additive for conductivity enhancement) (10:1:1.5 in weight ratio) on a piece of $\mathrm{Cu}$ foil. For referencing purposes, a pure $\mathrm{Ga}$ electrode was prepared by spreading liquid Ga on a piece of Mo foil using a slide glass. The Mo foil selected as the alloy formation between $\mathrm{Ga}$ and $\mathrm{Mo}$ was negligible. $\mathrm{Cu}$ foil forms an alloy with $\mathrm{Ga}$. The galvanostatic charge/discharge cycling was made in the potential range $0.0-2.0 \mathrm{~V}$ at $100 \mathrm{~mA} \mathrm{~g}^{-1}$ with a two-electrode 2032 cointype cell, where Li metal foil was used as the counter electrode. A mixture of $1.0 \mathrm{M} \mathrm{LiPF}_{6}$ with ethylene carbonate and dimethyl carbonate $(1: 1 \mathrm{v} / \mathrm{v})$ was used as the electrolyte. A glass fiber sheet and polypropylene film were used as the separator for the pure $\mathrm{Ga}$ and $\mathrm{Ga}-\mathrm{C}$ composite electrode, respectively. Cells were assembled in an Ar-filled glove box and cycled at 35 and $55^{\circ} \mathrm{C}$. In this article, the lithiation (alloying) is expressed as discharging, whereas the delithiation (dealloying) is expressed as charging.

\section{Results and Discussion}

Preparation and characterization of liquid Ga-confined porous carbon.- The synthetic procedure for liquid $\mathrm{Ga}-\mathrm{C}$ is presented in Scheme 1 . In detail, the starting material was nanosized $\mathrm{Ga}_{2} \mathrm{O}_{3}$ powder that was obtained by high-energy ballmilling of micrometersized $\mathrm{Ga}_{2} \mathrm{O}_{3}$ powder. The TEM image of milled $\mathrm{Ga}_{2} \mathrm{O}_{3}$ powder is displayed in the inset of Fig. 1a, wherein the $\mathrm{Ga}_{2} \mathrm{O}_{3}$ particles show an irregular shape $<50 \mathrm{~nm}$ in size. When the mixture of nanosized 


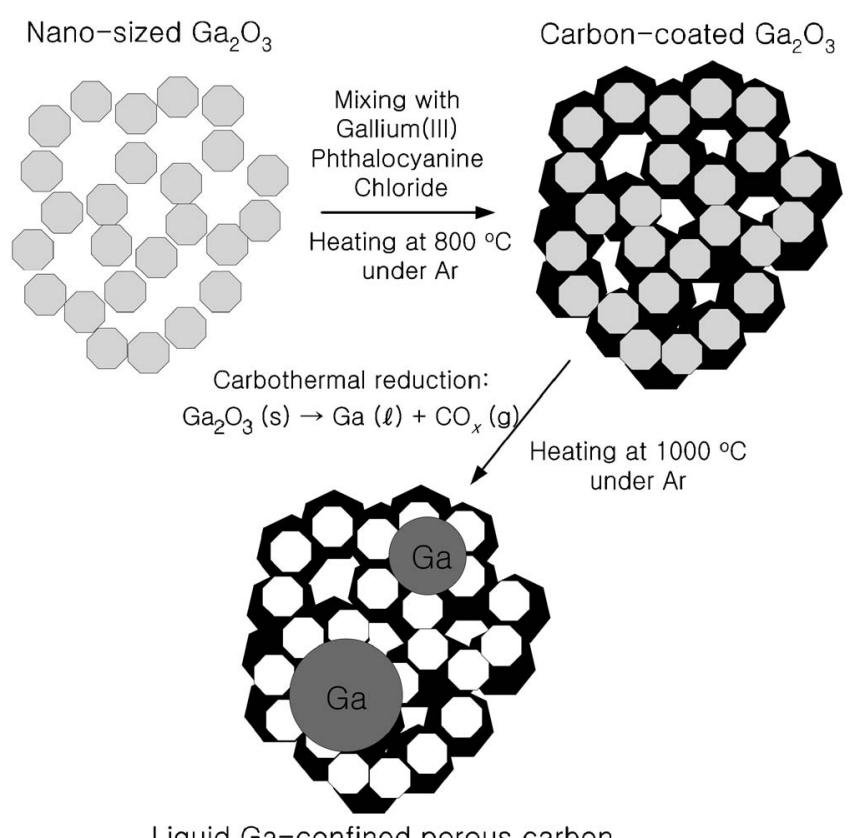

Liquid Ga-confined porous carbon

Scheme 1. Synthetic scheme for a liquid Ga-confined porous carbon.

$\mathrm{Ga}_{2} \mathrm{O}_{3}$ powder and gallium(III) phthalocyanine chloride was heated at $800^{\circ} \mathrm{C}$ under $\mathrm{Ar}$ atmosphere, gallium(III) phthalocyanine chloride was vaporized and carbonized, such that the $\mathrm{Ga}_{2} \mathrm{O}_{3}$ particles were embedded inside carbon matrix, as shown in Fig. 1 a. ${ }^{16,17}$ The XRD pattern obtained with this sample gives the diffraction peaks belonging to $\mathrm{Ga}_{2} \mathrm{O}_{3}$ and amorphous carbon (Fig. 2). The XRD pattern obtained with the sample heat-treated at $1000^{\circ} \mathrm{C}$ reveals that two overlapping broad peaks appear at $30-50^{\circ}$ at the expense of $\mathrm{Ga}_{2} \mathrm{O}_{3}$ peaks, indicating that the $\mathrm{Ga}_{2} \mathrm{O}_{3}$ is carbothermally reduced to elemental liquid gallium; $\mathrm{Ga}_{2} \mathrm{O}_{3}(\mathrm{~s})+\mathrm{C}(\mathrm{s}) \rightarrow \mathrm{Ga}(\mathrm{l})+\mathrm{CO}_{x}(\mathrm{~g}){ }^{18,19}$ The bright-field TEM image taken with this sample shows a liquid Ga grain embedded in carbon matrix (Fig. 1b). It is noteworthy that the Ga grain is round-shaped and its diameter larger than that of the initial $\mathrm{Ga}_{2} \mathrm{O}_{3}$ particles, which must be due to a particle growth caused by high surface tension and cohesive forces inherent to liquid Ga. The bright-field TEM image also illustrates the presence of pores that can be recognized as the lighter image in Fig. 1b. It is likely that the pores are generated at the space where $\mathrm{Ga}_{2} \mathrm{O}_{3}$ particles are located before carbothermal reduction. During the carbothermal reduction, liquid $\mathrm{Ga}$ droplets form but move out to cohere with nearby Ga droplets to leave a pore on that space. Pores can also be formed by burning-off the carbon wall by oxygen atoms from $\mathrm{Ga}_{2} \mathrm{O}_{3}$. The pores shown in Fig. $1 \mathrm{~b}$ are irregular in shape and unevenly distributed, which may be caused by a movement of liquid Ga droplets. It is likely that such a movement leads to a high mechanical deformation on the carbon matrix. Figure 3 presents the pore-size distribution that was calculated by the Barrett-JoynerHalenda method from the adsorption branch of the nitrogen isotherm. The pores of ca. $30 \mathrm{~nm}$ diameter are dominant in Ga-C. The pore volume and Brunauer-Emmett-Teller surface area of this sample were $0.073 \mathrm{~cm}^{3} \mathrm{~g}^{-1}$ and $55.6 \mathrm{~m}^{2} \mathrm{~g}^{-1}$, respectively. Summarizing the morphological studies presented above, the $\mathrm{Ga}-\mathrm{C}$ sample can be depicted as a liquid Ga-embedded, spongelike carbon. The TGA made on this sample indicates that the Ga content is $28.1 \mathrm{wt} \%$, which was calculated on the basis of an assumption that $\mathrm{Ga}(\mathrm{l})$ and carbon are converted to $\mathrm{Ga}_{2} \mathrm{O}_{3}(\mathrm{~s})$ and $\mathrm{CO}_{x}(\mathrm{~g})$, respectively, during the TGA analysis made in air.

Electrochemical characterization of liquid Ga-confined porous carbon electrode.- Saint and co-workers performed an electrochemical study on a $\mathrm{Li}_{2} \mathrm{Ga} / \mathrm{Li}$ cell at room temperature, wherein the
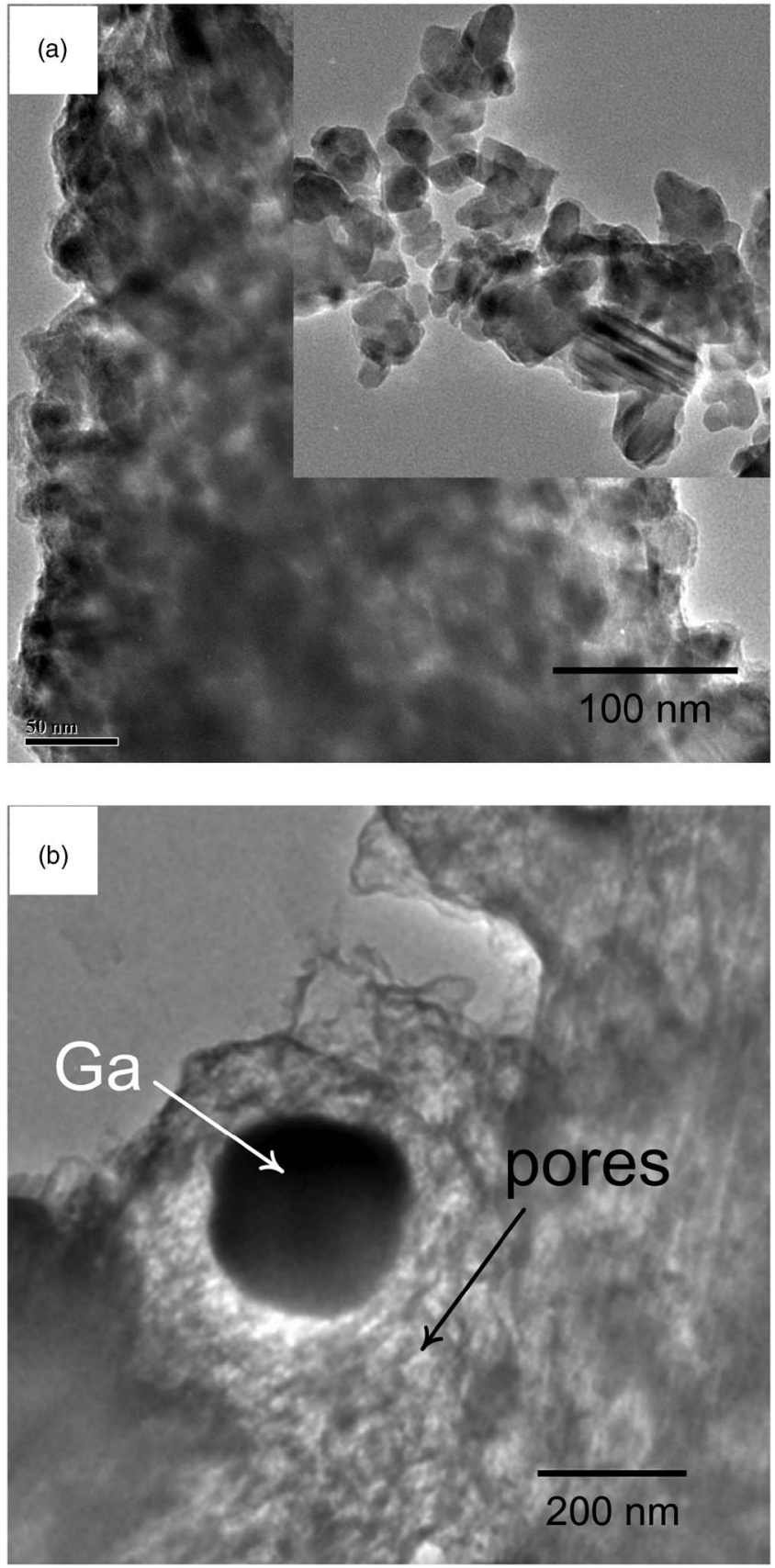

Figure 1. HR-TEM images of (a) carbon-coated $\mathrm{Ga}_{2} \mathrm{O}_{3}$ powder and (b) liquid Ga-confined porous carbon. The image for ballmilled $\mathrm{Ga}_{2} \mathrm{O}_{3}$ powder is provided in the inset of (a).

$\mathrm{Li}_{2} \mathrm{Ga}$ powder was prepared by mechanical ballmilling of a $\mathrm{Ga}$ and Li mixture. ${ }^{20}$ Based on the in situ XRD analysis, they proposed that $\mathrm{Li}_{2} \mathrm{Ga}$ is delithiated to liquid $\mathrm{Ga}$ and recovered to $\mathrm{Li}_{2} \mathrm{Ga}$ upon lithiation, $\mathrm{Li}_{2} \mathrm{Ga}(\mathrm{s}) \leftrightarrow \mathrm{LiGa}(\mathrm{s}) \leftrightarrow \mathrm{Li}_{2} \mathrm{Ga}_{7}(\mathrm{~s}) \leftrightarrow \mathrm{Ga}(1)$. We made a similar in situ XRD measurement on a pure liquid $\mathrm{Ga} / \mathrm{Li}$ cell at $30^{\circ} \mathrm{C}$. Even if our measurement was made with a liquid $\mathrm{Ga}$ electrode rather than $\mathrm{Li}_{2} \mathrm{Ga}$, the same reversible reaction pathway was confirmed; thus, the results were not duplicated in this report.

Figure $4 \mathrm{a}$ represents the first discharge (lithiation)/charge (delithiation) voltage profile of pure Ga electrode that was obtained at $55^{\circ} \mathrm{C}$, which is higher than the melting point of Ga. Three voltage plateaus are apparent in both discharge and charge profiles, which reflects that $\mathrm{Li}^{+}$uptake/extraction proceeds via three consecutive two-phase reactions. It is also apparent that one Ga atom is lithiated 


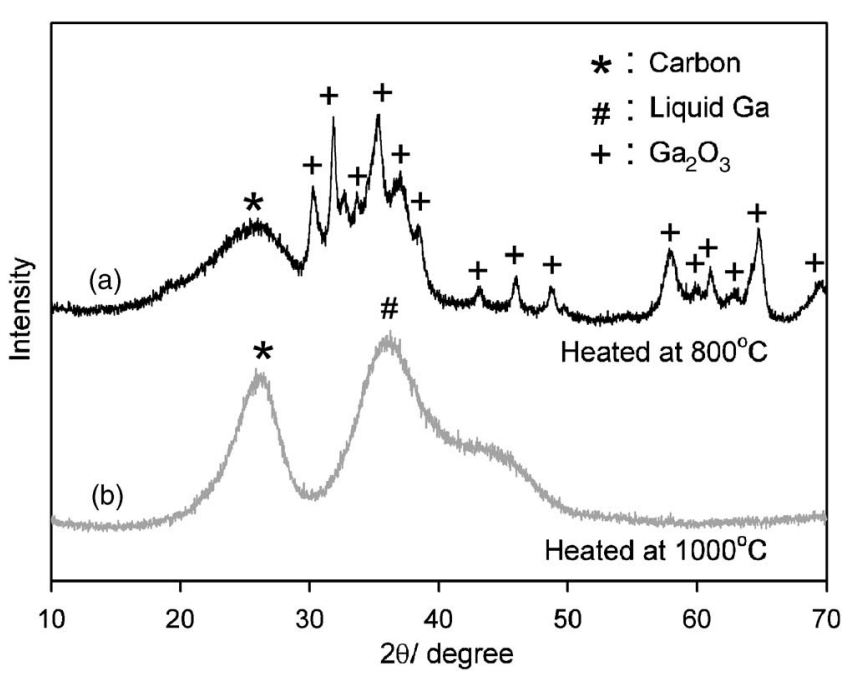

Figure 2. XRD patterns of (a) the carbon-coated $\mathrm{Ga}_{2} \mathrm{O}_{3}$ powder that was obtained by heating at $800^{\circ} \mathrm{C}$ and (b) the liquid Ga-confined porous carbon obtained by heating at $1000^{\circ} \mathrm{C}$.

with up to two $\mathrm{Li}$ atoms $\left(\mathrm{Li}_{2} \mathrm{Ga}\right.$, theoretical specific capacity $\left.=769 \mathrm{~mA} \mathrm{~h} \mathrm{~g}^{-1}\right)$. The Ga-C electrode shows somewhat different voltage profiles to that of pure $\mathrm{Ga}$ electrode, even if the measurement temperature was the same at $55^{\circ} \mathrm{C}$. The discharge/charge capacity is smaller than that of pure $\mathrm{Ga}$; moreover, three voltage plateaus are not clearly identified. The first irreversible capacity is larger than that for pure Ga electrode, which presumably came from an electrolyte decomposition and concomitant solid electrolyte interface (SEI) formation on the phthalocyanine-derived carbon. SEI formation on the Ga surface seems to be insignificant, as evidenced by the voltage profile of the $\mathrm{Ga} / \mathrm{Li}$ cell shown in Fig. 4a. A careful inspection of the voltage profiles recorded at $55^{\circ} \mathrm{C}$ for two electrodes reveals that the lithiation voltage (the downward profiles) is lower for the $\mathrm{Ga}-\mathrm{C}$ electrode, indicative of larger lithiation overpotential being involved in this electrode. Even lower lithiation voltage and smaller capacity observed at lower temperature $\left(35^{\circ} \mathrm{C}\right)$ suggests that the lower lithiation voltage for $\mathrm{Ga}-\mathrm{C}$ electrode is caused by kinetic origins. The larger overpotential may be accounted for by a lower electrical conductivity of $\mathrm{Ga}-\mathrm{C}$ electrode as compared to that of pure liquid $\mathrm{Ga}$. It is not difficult to assume that the electrical

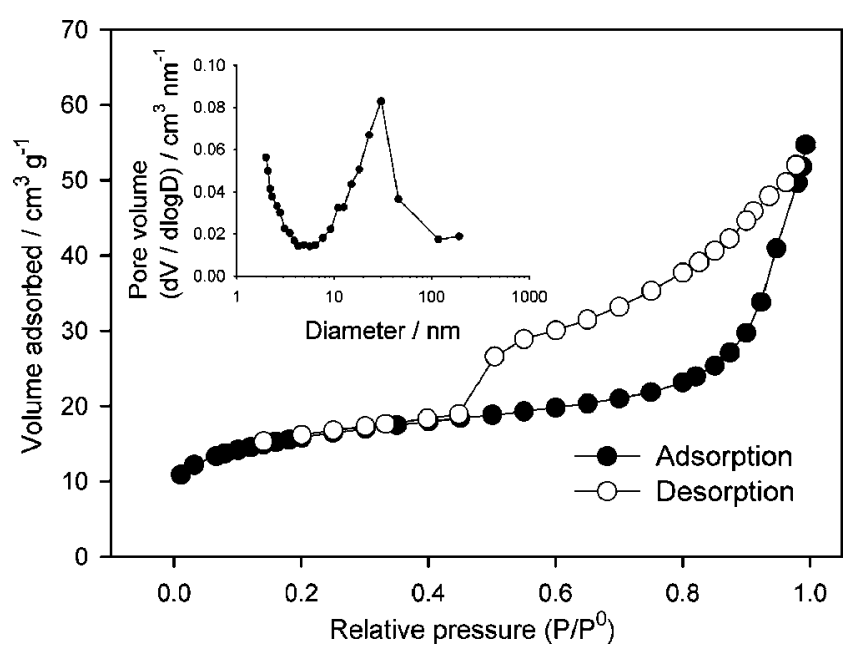

Figure 3. The $\mathrm{N}_{2}$ adsorption and desorption isotherm of a liquid Gaconfined porous carbon and the corresponding pore size distribution that was calculated from the adsorption branch of the $\mathrm{N}_{2}$ isotherm (inset).
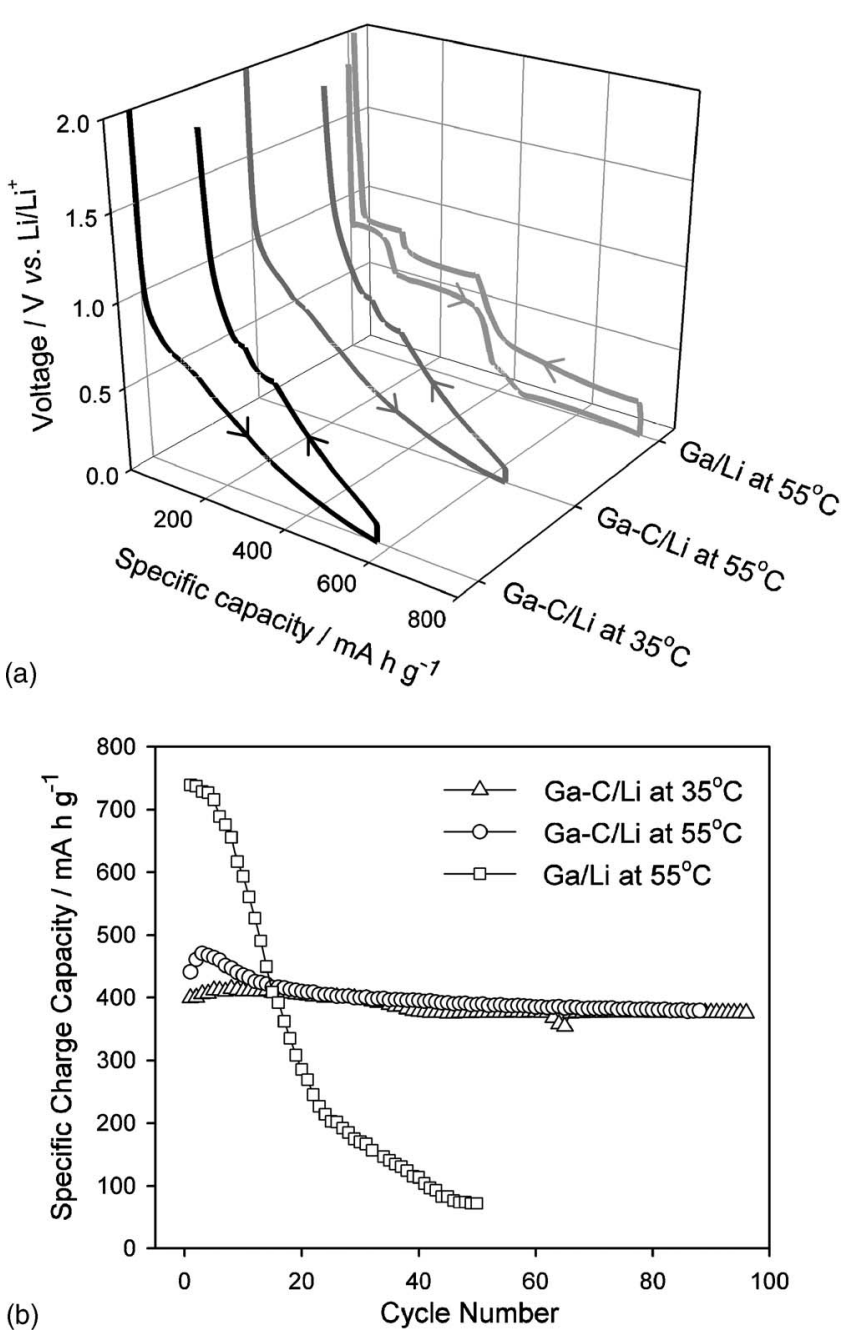

Figure 4. (a) Discharge (downward) and charge (upward) voltage profiles of a $\mathrm{Ga} / \mathrm{Li}$ and $\mathrm{Ga}-\mathrm{C} / \mathrm{Li}$ cell in the first cycle and (b) specific charge (delithiation) capacity as a function of cycle number.

conductivity of the metal/carbon composite electrodes is lower than that for pure metal film electrodes. The cycle performance was compared for the pure $\mathrm{Ga}$ and $\mathrm{Ga}-\mathrm{C}$ electrode in Fig. 4b. The pure $\mathrm{Ga}$ electrode shows a rapid capacity decay, whereas the Ga-C electrode shows a very good cycle performance with a charge (delithiation) capacity that amounts to $400 \mathrm{~mA} \mathrm{~h} \mathrm{~g}$.

The poor cycle performance observed with pure Ga electrode (Fig. 4b) is discouraging, because one can expect a restoration to liquid $\mathrm{Ga}$ after a lithiation/delithiation cycle, which eventually coheres to each other to be self-healed. In order to see if the restoration is complete in this electrode, XRD measurements were made at the end of the delithiation with cell cycling. If the restoration is complete, XRD patterns should give only the broad peaks belonging to liquid Ga phase. Figure 5a shows the XRD profiles recorded with pure $\mathrm{Ga}$ electrode. After the first charge (delithiation), the diffraction peaks for $\mathrm{Li}_{2} \mathrm{Ga}_{7}$ phase are still detected, in addition to the broad peak of liquid Ga near $35^{\circ}$, indicating that the restoration is not completed. The population of lithiated $\mathrm{Ga}\left(\mathrm{Li}_{x} \mathrm{Ga}\right)$ phases becomes larger with continued cycling, as evidenced by the steady growth of diffraction peaks for $\mathrm{LiGa}$ and $\mathrm{Li}_{2} \mathrm{Ga}$ phases. The XRD patterns taken with the Ga-C electrode (Fig. 5b), however, indicate that the population of lithiated $\mathrm{Ga}\left(\mathrm{Li}_{x} \mathrm{Ga}\right)$ phases in the charged electrode is much smaller than that for the pure Ga electrode. Even after 20 cycles, only a trace amount of LiGa is detected, indicative of almost complete conversion to liquid $\mathrm{Ga}$. 

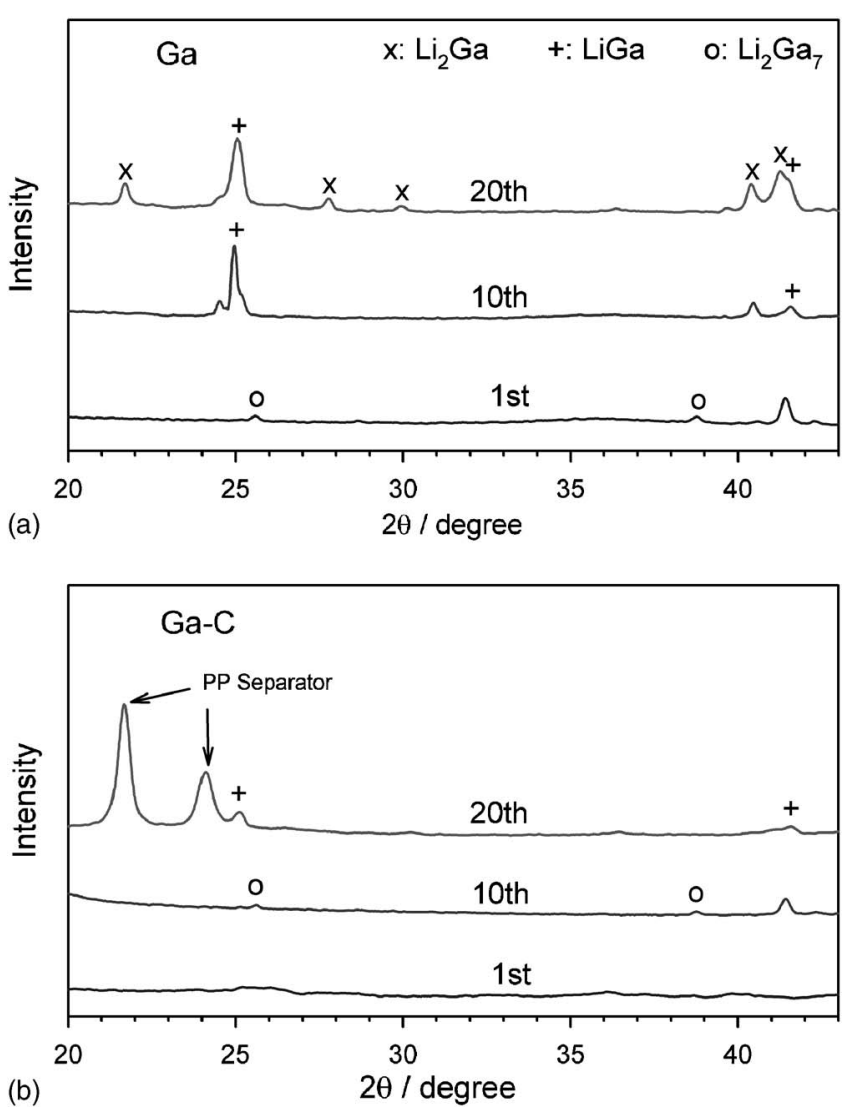

Figure 5. XRD patterns taken after delithiation with continued cycling: (a) pure $\mathrm{Ga}$ electrode and (b) $\mathrm{Ga}-\mathrm{C}$ electrode. Note the presence of lithiated $\mathrm{Ga}$ $\left(\mathrm{Li}_{x} \mathrm{Ga}\right)$ phases in the charged electrodes.

The capacity fading observed with pure Ga electrode can now be accounted for by the incomplete delithiation. As mentioned above, the liquid $\mathrm{Ga}$ electrode experiences several solid-state $\mathrm{Li}_{x} \mathrm{Ga}$ phases upon $\mathrm{Li}^{+}$uptake/extraction, which must be accompanied by a massive volume change. Therefore, a breakdown of electrical conductive network is expected along with crack formation and detachment of $\mathrm{Li}_{x} \mathrm{Ga}$ particles from the current collector until the solid-state $\mathrm{Li}_{x} \mathrm{Ga}$ phases are converted to liquid $\mathrm{Ga}$. At the end of delithiation period, however, the electrically connected $\mathrm{Li}_{x} \mathrm{Ga}$ particles would be converted to liquid $\mathrm{Ga}$ but the isolated ones remain as lithiated $\mathrm{Ga}$ phases. Due to the accumulation of lithiated Ga phases with repeated cycling, the $\mathrm{Li}^{+}$storage sites that are available for discharging (lithiation) become smaller, which is reflected as a gradual decrease in the charge capacity as shown in Fig. $4 \mathrm{~b}$.

The better cycle performance observed with $\mathrm{Ga}-\mathrm{C}$ electrode can now be ascribed to the favorable roles provided by the porous carbon matrix. First, the crack formation or any other problems that cause the electrical isolation of lithiated Ga particles may be suppressed by the squeezing action of the porous carbon matrix. That is, the carbon matrix can put pressure on the embedded Ga particles when they are expanded. Second, the detachment of Ga phases from the electrode layer may be greatly reduced because the Ga component is confined inside the carbon matrix. Due to these favorable roles, the electrically isolated $\mathrm{Li}_{x} \mathrm{Ga}$ particles may be greatly reduced to allow an almost complete restoration to liquid $\mathrm{Ga}$. If the restoration is complete in the first cycle, the second lithiation capacity would be comparable to that for the first cycle, because the Ga component can be lithiated as much as for the first cycle. Along this line, the $\mathrm{Ga}-\mathrm{C} / \mathrm{Li}$ cell shows excellent cycle performance without serious capacity decay (Fig. 4b).

\section{Conclusion}

In this article, the concept of self-healing has been ascertained with a liquid Ga electrode. We observed a restoration to initial liquid phase even after several solid-state lithiation/delithiation reactions that lead to a crack formation and detachment with a massive volume change. The self-healing was, however, unsatisfactory without the confining matrix. Hence, the presence of a confining porous matrix seems to be critically important to implement the self-healing approach. The extension of this approach seems limited if one considers the number of metals that are present as liquid at ambient temperature. We know, however, that there are numerous eutectic alloys that have a low melting point, for instance, Ga-In (75.4:24.5 in weight ratio, melting point $=15.7^{\circ} \mathrm{C}$ ). A study of these eutectic alloys is now underway in this laboratory.

\section{Acknowledgments}

This work was supported by the Korean Science and Engineering Foundation via the Research Centre for Energy Conversion and Storage.

Seoul National University assisted in meeting the publication costs of this article.

\section{References}

1. M. Winter, J. O. Besenhard, M. E. Spahr, and P. Novak, Adv. Mater, 10, 725 (1998)

2. J. Yang, M. Wachtler, M. Winter, and J. O. Besenhard, Electrochem. Solid-State Lett., 2, 161 (1999).

3. M. D. Fleischauer, J. M. Topple, and J. R. Dahn, Electrochem. Solid-State Lett., 8, A137 (2005)

4. K. D. Kepler, J. T. Vaughey, and M. M. Thackeray, Electrochem. Solid-State Lett., 2, 307 (1999).

5. T. D. Hatchard and J. R. Dahn, J. Electrochem. Soc., 151, A838 (2004).

6. R. B. Lewis, A. Timmons, R. E. Mar, and J. R. Dahn, J. Electrochem. Soc., 154, A213 (2007)

7. Y. Wang, J. Y. Lee, and H. C. Zeng, Chem. Mater, 17, 3899 (2005)

8. J. H. Ryu, J. W. Kim, Y. E. Sung, and S. M. Oh, Electrochem. Solid-State Lett., 7, A306 (2004).

9. I. A. Courtney, W. R. McKinnon, and J. R. Dahn, J. Electrochem. Soc., 146, 59 (1999).

10. H. Li, L. Shi, W. Lu, X. Huang, and L. Chen, J. Electrochem. Soc., 148, A915 (2001).

11. Y. Wang and J. Y. Lee, Angew. Chem. Int. Ed., 45, 7039 (2006).

12. K. T. Lee, Y. S. Jung, and S. M. Oh, J. Am. Chem. Soc., 125, 5652 (2003).

13. M. Yoshio, H. Wang, K. Fukuda, T. Umeno, N. Dimov, and Z. Ogumi, J. Electrochem. Soc., 149, A1598 (2002).

14. S. Park, T. Kim, and S. M. Oh, Electrochem. Solid-State Lett., 10, A142 (2007).

15. Y. S. Jung, K. T. Lee, J. H. Ryu, D. Im, and S. M. Oh, J. Electrochem. Soc., 152, A1452 (2005).

16. T. Kim, S. Park, and S. M. Oh, Electrochem. Commun., 8, 1461 (2006).

17. H. C. Choi, J. Park, and B. Kim, J. Phys. Chem. B, 109, 4333 (2005).

18. K. Wang, X. He, L. Wang, J. Ren, C. Jiang, and C. Wan, J. Electrochem. Soc., 153, A1859 (2006).

19. K. Wang, X. He, J. Ren, C. Jiang, and C. Wan, Electrochem. Solid-State Lett., 9, A320 (2006).

20. J. Saint, M. Morcrette, D. Larcher, and J. M. Tarascon, Solid State Ionics, 176, 189 (2005). 